\title{
Contemporary collaborations between museums and universities
}

\section{Experiences from a large Danish research program}

\author{
Line VestergaARd Knudsen \& Celia Ekelund Simonsen
}

\begin{abstract}
Numerous new types of cross-institutional collaborations have been conducted recently at the intersection between museums and universities. Museums of all subject areas have collaborated with university researchers, just as scholars from a broad range of disciplines including communications, media studies, IT and performance design and tourism increasingly collaborate with museums.

Based on qualitative evaluation material and autobiographical experiences, this article analyzes a large Danish research project in which collaborations between several museums and universities took place. We investigate how university researchers contributed to the development of museum practices as well as how involvement in museum projects contributed to university research; we then discuss the various professional and practical challenges such collaborations face. Particularly we emphasize "anchorage" as a significant multidimensional concept that was critical to the collaboration outcomes and challenges. By this focus we aim to contribute to future cross-institutional collaborations between museums and universities.
\end{abstract}

Keywords: Museum, university, cross-institutional, collaboration, museumaudience communication, evaluation.

This article evaluates a large cross-institutional research program that involved a range of museums, universities, and research fields between 2009 and 2015. We see the numerous projects in this program as examples of the type of cross-institutional collaborations between museum professionals and university researchers that have flourished in recent years. "Collaboration" may simply be defined as the act of working "jointly with others, or together, especially in an intellectual

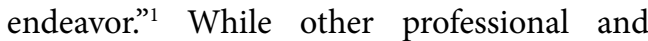
academic fields have developed more precise definitions of collaboration, co-operation and partnership, these concepts tend to be more vague in the museum sector (Cooper 2013). This article evaluates several crossinstitutional collaboration projects in a wide range of forms that could interchangeably be labeled by all three concepts. We ask which 
mutual contributions and challenges arose in these collaborations. Both authors of this article were engaged as $\mathrm{PhD}$ students in the program.

\section{MUSEUM-AUDIENCE COMMUNICATION}

This article examines in particular crossinstitutional collaborations between museums and universities centered on museum-audience communication. Within the last decade, cultural policies, museums and university researchers have increasingly focused on how museums approach their audiences (those who visit museums) and the more general public. In this setting, museum-audience communication is widely seen as a central point for discussion and improvements within museum practices. Museum-audience communication contains both transmissions of knowledge and the cultural exchanges of perceptions, just as this form of communication is generally understood to be both mediated (exhibitions, books, and digital media) and unmediated (face-to-face teaching and dialogues) practices (Hooper-Greenhill 1999, Drotner \& Schrøder 2013).

In 2006, the Danish Ministry of Culture investigated Danish museums' competencies and results related to audience communication (Kyed et al. 2006); the ministry concluded that more professional and economic efforts should be put into this area. Museums were encouraged to facilitate wider and more representative contact with the public, to use new digital communication technologies to facilitate learning and to evaluate and document their audiences' receptions of the new developments (Kyed et al. 2006:98, Rudloff 2013). In accordance with these objectives, many museums have attempted to include external technical, practical, and academic resources to develop communications with their audiences and the wider public.

University researchers from a range of fields have also become increasingly aware of the potentials of museum-audience communication as a research field. A survey of the status of Danish museum research conducted by the Danish Centre of Museum Research (DCM) in 2014 showed that the majority of museum research projects conducted at universities focused on museum exhibitions, audience learning or communication (Gransgaard et al. 2014: 25).

While this article focus on collaborations centered especially on museum-audience communication we acknowledge that cross-institutional collaborations on museum collections, management, research, and conservation also exist and are developing.

\section{Cross institutional COLLABORATIONS}

As already mentioned, cross-institutional collaborations between museums and universities are on the rise these years. One reason might be that funding opportunities targeted at cultural heritage institutions and their audiencecommunication urge for such collaborations. For instance, the Danish Velux Foundation wishes to "strengthen collaboration, bridge building and interaction between museum researchers and educators, and universities researchers." ${ }^{2}$ A funding program of the British Arts and Humanities Research Council (AHRC) similarly urges museums and galleries to collaborate with arts and humanities research while working to attain high-quality "accessibility and visibility" 3 among audiences.

Over the last decade, Denmark's Ministry of Higher Education and Research has highlighted demands on universities' abilities 
90 to collaborate externally and to conduct research oriented toward application (and thus relevance) in society. Further, large public foundations such as The Innovation Fund Denmark wish to merge research and society by making "investments in cross-institutional projects that connect knowledge institutions with both private and public companies."4 The European Horizon 2020 program contains various sections that would be suitable for humanities research in which the "specific objective is to build effective cooperation between science and society". ${ }^{5}$ In these funding contexts, many university researchers have found museums attractive as collaborative partners.

Although it is beyond the scope of this article to further describe the relationships between cultural policy, funding strategies and the shaping of research collaborations between museums and universities, we do wish to suggest that political demands and resources directed into both the museum and university sectors have influenced the movement to embrace cross-institutional collaborations on museum-audience communication.

The various funding authorities and policies have provided minimal and/or multifarious guidance on the formats and types of collaboration that should be used, and therefore multiple collaborative forms have emerged. Some collaborations primarily consist of university research on topics of museum-conducted audience communication (e.g. Dodd et al. 2012). While such projects often challenge museums to reflect on their ways of communicating with their audiences, they do not act to design museum-audience communication per se. Other projects include active practical involvement by university researchers in which they have designed and installed exhibitions or digital-communication products in museum spaces. In some such projects close and continuous interactions between university and museum professionals are the rule (Davis et al. 2015); in other cases university researchers rather use the museum space as labs for testing academically driven ideas and innovations (Danko-McGhee 2004). In some projects, university researchers and museum professionals collaborate from the earliest stages to articulate project's focus and purpose (often in relation to design of a funding application), while in other projects, one party have developed key areas and objectives and then invited the other party to the project (MacLeod et al. 2014). Collaborations may also vary in their emphasis on university education (which implies students and $\mathrm{PhD}$ students) in projects versus engaging in more senior research activities based at the university. Cross-institutional collaborations between museums and universities thus have different organizations and role distributions.

\section{CURRENT RESEARCH ON CROSS- INSTITUTIONAL COLLABORATIONS}

Despite the increasing tendency for crossinstitutional collaboration between museums and universities, not many studies have reported on the processes, outcomes and challenges of such practices (Cooper 2013). However, we do find a few studies very relevant and worth mentioning in relation to our analysis and evaluation.

Kevin Crowley and Karen Knutson have worked for almost two decades to develop both informal museum learning and academic learning research. In two articles from 2005 (Crowley \& Knutson 2005, Knutson \& Crowley 2005), the authors summarized their experiences of working continuously together with the Children's Museum in Pittsburgh. 
The premise of this collaboration was that professionals at the museum recognized that they required a form of evaluation that could go beyond professional beliefs, experiences and hypotheses. This need paved the way for university researchers to conduct specific and evidence-based evaluations within the setting of the museum (Knutson \& Crowley 2005:4). As researchers, the authors found that the collaboration allowed them to ground theoretical approaches in real-world practical problems (2005:7). In addition, they stated that they benefited from "the opportunity to talk through [...] issues with museum practitioners, to engage in self-reflective conversations about how daily practice and daily research intersect with higher order theories and ideas" (Knutson \& Crowley 2005:4). They also found the mutual pursuit of common ground and trust to be critical to successful museum-university collaborations.

In the Danish magazine Danske Museer (Danish Museums), two museum professionals and a university researcher/teacher reflected on their experiences during a museum exhibition collaboration involving students of "applied cultural analysis". ${ }^{6}$ The students, with their theory-based competencies, were able to identify and generate nuanced cultural analytical concepts that combined exhibition subject issues and audience perceptions, such as "youth" and "borders" (Madsen et al. 2014). Such concepts were useful in further development of museum exhibitions. In addition, the museum staff found that the students contributed a methodological and reflective consciousness regarding museum communications. The collaboration benefitted the university study program by developing the students' ability to make their analytical findings relevant and applicable to external partners' needs. The authors saw adjustment of expectations as critical to successful collaborations; the products of the students' involvement had to be clearly demarcated beforehand, and the museum partners had to acknowledge and accept the scholarly obligations included in the collaborations (Madsen et al. 2014).

Apart from the few studies discussed thus far - and although many cross-institutional university-museum collaborations take place in Denmark and abroad - the literature lacks reports and discussions on collaborations between museums and universities. Because the number of such collaborations is steadily growing, we find it especially important to explore the experiences of contributions and challenges to develop this area of practice and research.

\section{THE DREAM PROGRAM}

The following section describes the content and organization of the Learning 2.0: Digital Literacies and Innovation program (henceforth "Learning 2.0") at the Danish Research Centre on Education and Advanced Media Material (DREAM) within which all the collaborations discussed in this article took place. Between 2009 and 2015, eight $\mathrm{PhD}$ researchers, two post-doctoral researchers, a steering group of four senior university researchers, and ten museums were involved in the program. ${ }^{7}$ (For more information on the program, see Drotner 2013.)

The overall aim of the program was to investigate how digital media and learning resources facilitate creativity and learning; the question was formulated by senior university researchers from three Danish university departments: Communication Studies, and Roskilde University at Department of Science Learning, and Department for the Study of 
Culture, both at the University of Southern Denmark. The senior researchers found that the various methods for answering this question should be humanistic co-design, implementation and evaluation processes.

The senior researchers chose museums as empirical fields, since they assumed that museums' semi-formal learning environments would better facilitate alternative learning styles than the formal education system. Museums of art, history and natural history, as well as science centers and an aquarium, agreed to take part in the collaboration in relation to specific projects (already planned by the museums) that matched the program's objectives. Some of the participating museums were long-standing institutions with decades of continuous experience with their audiences, while others were still in the founding/building stages.

Funding came from three sources: a grant from the Danish Research Council for Strategic Research covered roughly 60 per cent of the overall budget of 45 million DKK,${ }^{8}$ university faculties covered another 35 per cent, and participating museums and science centers contributed in-kind funding totaling 5 per cent of the budget. The biggest expenses in the program budget consisted in wages of university researchers. $\mathrm{PhD}$ students and post-docs with scholarly backgrounds in learning, ethnology, archeology, IT-design, and communication and media studies were recruited for the projects formulated in the program. In most projects, a museum hosted a $\mathrm{PhD}$ student to collaborate on a specific digital learning and communication project. As examples, a new digital installation for exhibition use (Vestergaard 2012), a web platform that worked as an online extension of the museum (Knudsen 2015), a mobile app used for a science center school workshop

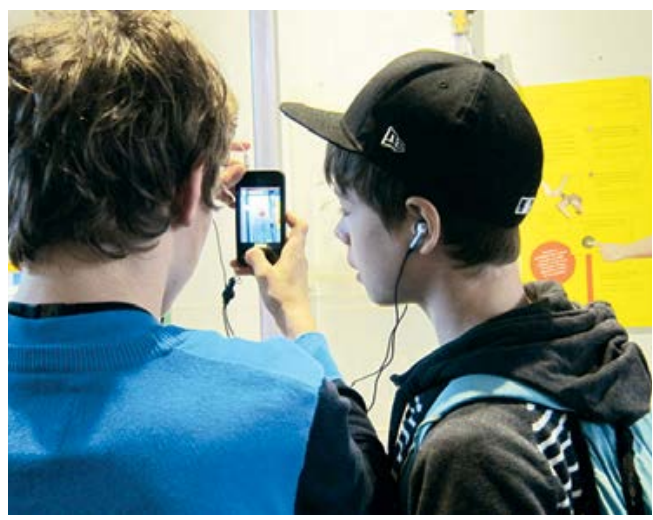

Fig. 1. Mobile app for a science center school workshop at Experimentarium. Photo: Line Vestergaard Knudsen.

(Simonsen 2016) and several iPad learning tools (Gronemann 2016) were produced from these collaborations. Other projects, (which included several museums), explored existing digital learning tools (Kobbernagel 2013, Laursen 2013, Raith 2016) or examined the collaborations between museums and creative industries when creating digitalcommunication technologies (Olesen 2015). Several projects followed developmental processes at length while others were primarily involved in specific stages of digital communication development. The balance between being observing evaluators and/ or active participants in the development processes thus varied. The senior researchers in the program acted as supervisors for the $\mathrm{PhD}$ researchers, while museum professionals acted as external advisers for the scholars' academic work. The authors of this article were engaged in projects in which both evaluation and digital-communication design were at stake.

To summarize, the program had several significant objectives, including investigating 
creative learning through museum-audience communication, conducting investigations by the use of various design and evaluation methods, creating and strengthening networks across institutions and disciplines, and educating researchers. The senior university researchers primarily held the power to make program-related decisions, although the participating museums' aims and challenges vis-à-vis the collaborations were continuously monitored throughout the programs' duration. And, as noted earlier, the specific museum development projects engaged in the DREAM program had all been initiated at the museums themselves as part of their own exhibition, education, or other communication programs.

\section{APProach AND METhod}

Based on evaluation conversations between several program participants from the museums and universities, this article analyzes and evaluates the DREAM museum-university collaborations. We include transcribed audiodata material from evaluation conversations as well as autobiographical descriptions and reflections of various issues.

Because the evaluation conversations took place when most collaborative projects had been finalized, most of the experiences and opinions were retrospective. All program participants met and were subdivided into three groups of approximately seven participants, mixed between museum professionals and university researchers; each conducted an evaluation conversation. The conversations were partly open-ended, because they took the form of strengths, weaknesses, opportunities and threats (SWOT) analyses. The participants were not prodded to speak about specific aspects of the DREAM program but were encouraged to describe the more positive as well as the more negative aspects of the program

and the respective project collaborations.

The authors of this article had originally considered conducting an interview-based study with selected program participants that would focus on the contributions and challenges of the collaborations in the program, but we came to welcome the SWOT conversations the senior researchers had planned as suitable alternatives to an interview-based study. The format of the conversations and dialogues could enhance participants' reflections and considerations about the program processes. Although we knew the method would not allow us to choose and direct the topics of conversations and we knew that some parts of the SWOT conversations would be irrelevant to our analysis. Thus, we did not formulate the analysis and evaluation in the article as a robust SWOT analysis but instead analyzed parts of the three SWOT conversations (indicated in this paper as Conversations $\mathrm{x}, \mathrm{y}$, and $\mathrm{z}$ ) in combination with our own observations and experiences as DREAM participants. General contributions and challenges related to the collaborative aspects of projects served as themes in the coding; over time, the concept of "anchoring" emerged as a pivotal point in the material.

\section{Analysis AND evaluation}

This section presents an analysis in two parts. First, we report on the general contributions of the DREAM collaborations according to the participating museum professionals and university researchers. Second, we present "anchorage" as a significant multidimensional concept that was critical to the collaboration outcomes and challenges.

Evaluating a large and complex program that involved many institutions, projects and 
participants certainly involves many complications; evaluating the outcomes of collaborations and projects soon after conclusion of a program also has difficulties. Along with the empirical data the evaluation conversations offered (as well as the insights we gained from our own participation in the program), we have focused our analysis and evaluation particularly on the organization and unfolding of collaboration processes within the single projects. We have not evaluated the overall research results of the program or the ongoing leadership of the program, the social and professional networks that were formed during the program, or the political indices that influenced the program; nor have we evaluated the specific products or audience experiences that came out of the collaborations. Instead, we primarily view this evaluation as a contribution to the research and planning of collaborative aspects of museumuniversity projects.

\section{Contributions}

The participating museum professionals emphasized that the collaborations had provided knowledge on different levels. Some researchers brought new forms of concrete knowledge or tools to the projects that would help in the development phase. As one participant stated, "we didn't have any digital learning tools before he [a PhD student] worked with us, but now we have several" (Conversation $\mathrm{x}$ ). Some museum professionals stated that their research partners had challenged various practices related to communication-design processes. A specific and often mentioned contribution was the conducting of research-based evaluations; one project investigated digital-learning platforms used in the museum and in the classroom and pinpointed the learning potentials as well as challenges of each approach (Raith 2016). Such evaluations offered museum professionals a better basis for argumentation on the project development. Or maybe on other projects that followed:

When we let a 'baby' out in the world [i.e. a new digital-learning platform], we can see that it has users, but we don't know whether or not it works. Her work [a PhD student] has been indispensable; even though her results arrived too late to influence this design process, they'll influence future design processes (Conversation $\mathrm{x}$ ).

Some collaborations led to greater acceptance of research-based development of exhibitions and museum communication, which may have contributed to a rethinking of overall work practices. Some museum professionals emphasized that the researchers' orientation toward evaluation generally led to improvements in experience and knowledge transfer across projects in the institutions.

The researchers primarily stated that the collaborations provided open access to various empirical fields of museum communication. For some researchers, the study consisted of quantitative data collected and mined in evaluation studies, while most researchers spent large amounts of time at institutions conducting field-work and/or participating in project-development activities. These differences in appearance and participation among the researchers naturally influenced the type of empirical data the researchers acquired. Some of the researchers (Vestergaard 2012, Knudsen 2015, Gronemann 2016, Simonsen 2016) who were particularly involved in the practical tasks of developing digital-learning and communication projects viewed this engagement as both a privilege and a challenge; This includes the authors of this article: While we did gain insights into details within the 


\section{CONTEMPORARY COLLABORATIONS BETWEEN MUSEUMS AND UNIVERSITIES}

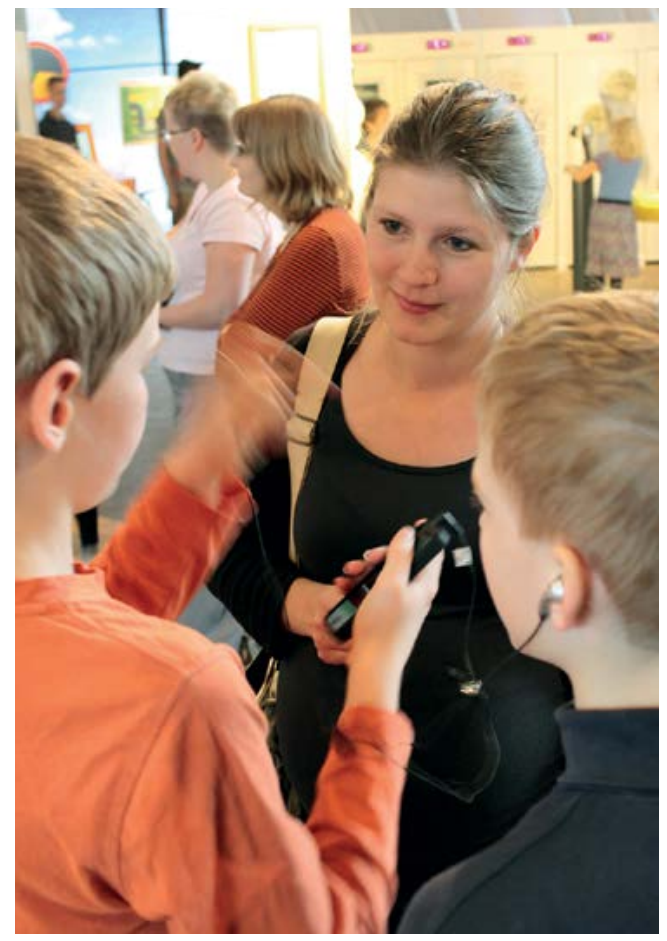

Fig. 2. Conducting interviews with school children for an evaluation study. Photo: Poul Kattler.

projects and could test our own ideas and theoretical concepts in the museum space with museum audiences, this level of participation posed several dilemmas regarding our roles in gathering the empirical data (and thus the auto-ethnographic character of our studies); we repeatedly had to reflect on what was actually museum practice and what were our own practices and influences in the process. Researchers who followed the development processes as more passive observers could view processes from a less self-invested viewpoint. They were sometimes detached from their museum's activities, however, since museum professionals might not contact and report to the researchers at every stage in the process.
These close and continuous contact between partners achieved in most projects made the university researchers more embedded in the institutional concerns, motivations and activities and thus created better conditions for alignment between research and museum practices. One researcher stated:

We've become better at having a tether back to practice so that we don't sit for three years and develop something and then come out and present our results to those in the practical field, only to have them say 'no'. We have a better insight into the field now (Conversation y).

This statement corresponds well with Madsen et al.'s findings (2014) mentioned earlier in this article.

Even as the university researchers primarily emphasized access as a benefit from the cross-institutional collaborations (access to studying and developing museum practices related to museum-audience communication), partnerships between museum professionals and the $\mathrm{PhD}$ researchers also resulted in continuous, collaborative reflections on the nature of topics such as learning, user involvement and digital communication in museum settings. Such interactions persuaded the authors of this article to include various subjects in their dissertation work - such as discussions of the dilemmas of digital audience participation in relation to diversity and legislative matters - that we otherwise may not have included.

\section{ANCHORAGE}

In addition to the benefits the museum professionals and university researchers in the DREAM collaborations gained, our analysis of the three evaluation conversations also 
suggested a series of challenges under the heading "anchorage".

By investigating the three evaluation conversations, we found that many of the participants emphasized tight interrelations as pivotal to the program strengths and/or weaknesses; participants often used the Danish word forankring, which we have translated as "anchorage" to maintain the anchor metaphor central to the Danish term. This term connotes staying connected and in sync rather than drifting apart. During the evaluation conversations, people viewed "anchorage" to be a positive factor for collaborations between university researchers and museum professionals. Participants also faced multiple challenges in attaining anchorage. Both in the conversation data and in our own retrospective reflections, we found different dimensions of anchorage based on form, content, time, and personal relations. The following sections present these four different dimensions.

\section{AnChorage: Form}

In the evaluation conversations, the university researchers and museum professionals agreed that the formal agreements that constituted the basis for almost all collaborations were an indispensable advantage. In addition to already having selected and formulated the specific research projects, the senior researchers had also put certain practical guidelines for the projects in place: University researchers should have a desk at the museum and spend time at the institution at least once a week. Each researcher should have a specific contact person at the museum. Researchers should participate in relevant meetings at the institution and regularly present progress of their project to their museum colleagues. By each project startup and once every six months, the $\mathrm{PhD}$ supervisor should conduct a meeting with the $\mathrm{PhD}$ student and the museum contact person in order to ensure the continuous calibration of mutual expectations and to evaluate the collaboration's and the project's progress. Mutual expectations should be elaborated on and agreed to early on; from then on supervisors should monitor whether the expectations were being met. Frameworks for collaborations were thus collectively set from the beginning and led to a type of formal anchorage that researchers and museum professionals overall found valuable as the anchorage served as a means for commonality and stability in the collaboration projects. As one museum professional said, "formalities are generally important" (Conversation z).

In practice, however, we also found that the presence of formalities did not always correspond to how things were done. For instance, continuously participating in staff meetings at the museum could be challenging for the $\mathrm{PhD}$ students, who also had to attend PhD courses and teach. Participants also emphasized that, despite projects being formulated beforehand and the formal guidelines being in place, all projects encountered challenges of defining precisely what the collaboration should contain, and how the collaboration should be done. One participant noted, "all projects have had some degree of uncertainty about what the actual collaboration should consist of. - An uncertainty that each researcher spent time considering and unravel" (Conversation $\mathrm{x})$. Some participants said they could have had "more space for clarification about projects" and more "plan B consciousness" (Conversation $\mathrm{x}$ ). Together with our own experiences, these findings lead us to conclude that pre-agreements on form and practicalities are important for securing anchorage, while 
partners must also accept uncertainties and be mutually conscious of the continuous need to resolve uncertainties about content, collaborative forms and tasks along the way. On a related note, we observed that $\mathrm{PhD}$-related formalities sometimes made researchers less flexible. In particular, the semi-annual $\mathrm{PhD}$ plans/reports that were to be submitted to university administrations, led some $\mathrm{PhD}$ students to make rushed decisions. Formal flexibility thus sometimes seemed easiest for the museum partner to attain.

\section{Anchorage: Content}

The DREAM research interests engaged various theories and methods from the fields of media, communication, learning, audience, organization, and design studies, many of which were unknown to the museum professionals. Different academic disciplines thus co-existed in the collaborations.

In most Danish museums today, research tends to focus on cultural, natural, or art history. Curators also communicate their knowledge, thereby practically engaging with various communication and media techniques. Some museums employ especially trained museum professionals to teach and develop learning resources and audience communication. Some aspects of theory and certain academic approaches related to communication, however, seemed to be more well known, usable, and/or adoptable (and thus valuable) to museum professionals than others were. For instance, Jerome Bruner et al.'s (1966) scaffolding theory, which Nina Simon (2010) recently re-applied, was easily adopted into the vocabulary and practices of several museum professionals in the program. Some museum professionals also referred to John Falk's (2009) typologies of "museum visitor experience and motivations" and used this model to argue for more varied, and socially oriented, types of learning and communication design.

Some overarching theoretical approaches, however, such as ones inspired by Science and Technology Studies, seemed less immediately relevant to the museum professionals. Such approaches required translations before they could be considered valuable in the museum context. For instance, one author of this article spent time and resources making the concepts of "complexity" and "productivity of difference" (Knudsen 2015:119-21) relevant and applicable in the collaborative setting of planning and conducting a digital-design process that would include audiences and other stakeholders. Such issues of making overarching disciplinary theory explicitly relevant to evaluations, practical solutions or design ideas (and vice versa) were a challenge during the development process and later when presenting analytical insights to museum professionals. In many projects, the overall theoretical approach of the university researcher remained an element of distance between them and the museum professionals. One researcher stated that "nobody was sitting there at the museum waiting for these theoretical research results to be reported" (Conversation $\mathrm{x}$ ). This distance was not all negative but was certainly a marker of the differently perceived values of the collaborations.

While overarching theoretical approaches did not often generate anchorages in the collaborative processes, participants did see the more empirical results of the evaluation research as doing this: "Evaluation is a good way to get familiarized with a museum and start dialogues with new museum colleagues" (Conversation y). Researching and evaluating museum communications provided the 


\section{Line VestergaArd Knudsen \& Celia Ekelund Simonsen}

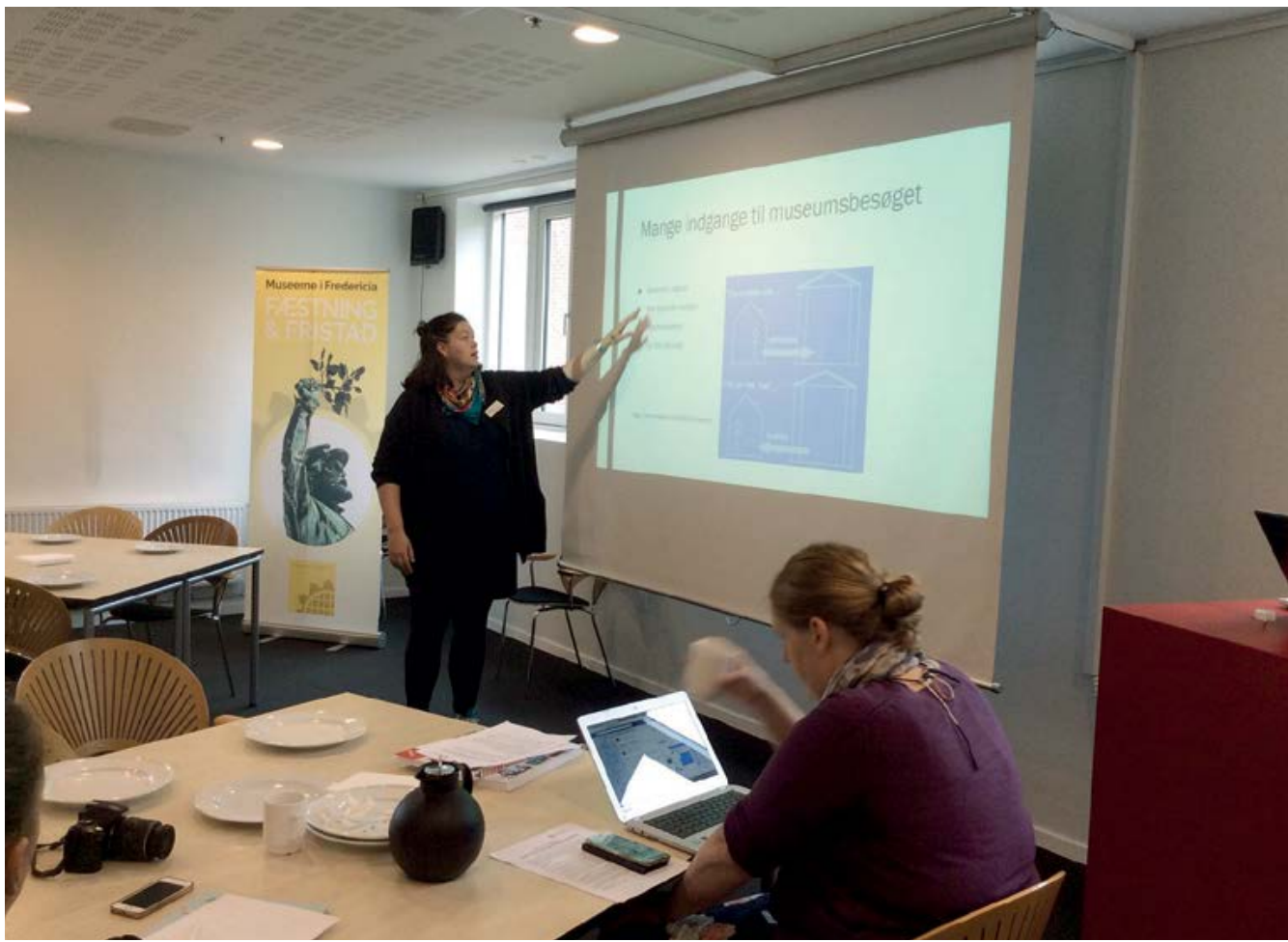

Fig. 3. PhD researcher reporting results of a study. Photo: Rasmus Helmin Kongstad Welling.

university researcher with knowledge of institutional practices, motivations, goals, and products, while the museum professionals (through the researchers' evaluations) were introduced to the interests, skills, knowledge and usefulness of the academic approach. As discussed earlier, some collaborations led to greater acceptance of research-based development of exhibitions and museum communications in museums than others. In these cases anchorage was created in the collaboration process, since researchers were able to demonstrate the value of evaluations in a convincing way and thus create common ground for content interest and knowledge between the university and the museum. Oppositely, some researchers had to acknowledge that it was impossible for them to influence current museum practice and thus anchor their evaluation results into the practices of that museum. One participant stated, "as a university researcher coming from the outside, it's difficult to be the one who turns around research and evaluation practices at a museum" (Conversation $\mathrm{x}$ ).

In their articles on museum-university collaboration, Knutson and Crowley emphasize the strengths that come from close collaborations in which researchers are engaged in evaluation and development, while members of the museum staff also contribute to the research agenda. They conclude that 
mutually shared interests, purposes and values can thereby be maintained (Crowley \& Knutson 2005:13). In the majority of the DREAM projects, this type of collaboration was not fully reached as university researchers and museum professionals often failed to find genuinely common and equally valued interests. In these cases university researchers' objectives in earning their degrees (which involved theoretical and scholarly work) could not be fully and explicitly integrated with the museum professionals' objectives of creating relevant and attractive learning and communication devices. As Knutson and Crowley also emphasize, however, such mutually shared agendas and purposes are typically not attained without many years of collaboration, knowledge sharing and trust building. Therefore, it would be very ambitious to expect such outcomes from these relatively time limited projects.

\section{Anchorage: Time}

A different type of anchorage produced by the evaluation conversations was related to time. The university and museum professionals viewed the temporality of research and museum practice as out of sync - as if "different forms of time between museums and universities" existed (Conversation y). The academic demands for research design and dissemination influenced the university researchers to become a fairly "slow" element, while the demands of museum exhibition and other audience-related project practices guided the museum professionals to move quickly. Several participants viewed this condition as a challenge to anchorage.

During the evaluation conversations, some participants suggested ways of coping with this mismatch in temporality, for instance by letting museum professionals follow the process of research closely to receive early insights from the research results or to collaborate on early formulations of best-practice guidelines on the basis of evaluation studies the researchers had conducted. These types of ongoing exchanges of information between museum professionals and researchers did take place in some of the projects. One museum professional stated, however, that "immediate embeddedness is not always preferred; sometimes, research is asynchronous and is something you need to wait for, digest, and reflect on afterwards" (Conversation $\mathrm{x}$ ). This statement signaled that this participant could also appreciate a certain distance between research and practice.

Several projects faced other temporalityrelated challenges. As an example, partnering museums might not be ready on time with the practical application or might change plans along the way. This situation would cause some researchers to have to wait for their object of study (such as a new exhibition or a digital installation) to be realized. This lack of a common temporality could lead to frustration among researchers, as their research activities relied on the production and use of certain museum communication products. In these cases, participants could find it difficult to substitute with another empirical object of study. We suggest that frustrations tied to lack of common temporality also had to do with the formalities of $\mathrm{PhD}$ research (as mentioned earlier), which in some cases does not easily allow for many changes and alterations after $\mathrm{PhD}$ plans have been submitted to and approved by the university administration.

\section{Anchorage: Personal relations}

Finally, personal matters and relationships occasionally affected the anchorages in the 


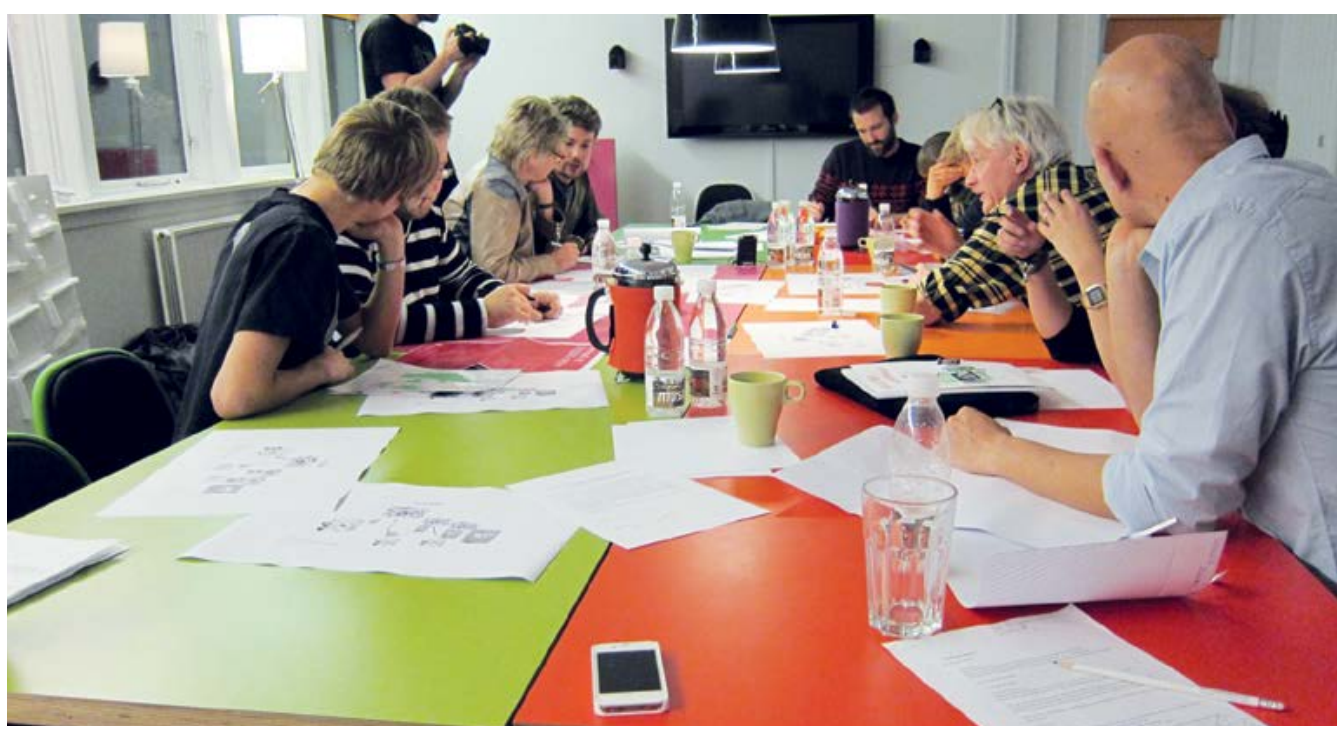

Fig. 4. Collaborating with museum professionals and museum users in designing a digital-communication platform. Photo: Line Vestergaard Knudsen.

project collaborations. Having dedicated contact persons at the museums connected to the researchers was of great importance to the collaborative processes in the projects. Even when some researchers participated in different projects with several project leaders in one museum, the contact person would remain the same, and thus a stable anchorage would be ensured through him or her. During the projects, however, this intention proved challenging in practice, for instance when a contact person found work elsewhere, changed positions within the museum, or was involved in several different projects at once within the institution. Researchers often had to adjust to working with different people during the research process, which in some cases led to a lack of anchorage between the $\mathrm{PhD}$ researcher and the museum institution, as well as between the museum institution and the DREAM program in general.
Another challenge was that some researchers experienced different contact needs with the institution during the research period. Researchers sometimes found project leaders and project members to be valuable collaboration partners; at other times, when evaluating projects and disseminating knowledge, researchers found that these personal contacts were inadequate for actually influencing processes in the institution. For instance, one $\mathrm{PhD}$ researcher stated that "it was difficult for me to be heard in the organization. It would have been preferable if someone who was higherranking in the organization than the contact person had been involved in DREAM as well" (Conversation y). For those researchers who hoped to contribute to organizational reflections and changes at a museum, they needed a connection to some of the leading persons in the institution; for others, having a connection to a communication-research staff 
member (if such a person existed) would be valuable. Thus, in order to be well connected to a museum institution (both for empirical data collection and the dissemination of research results), having one contact person was insufficient for most researchers. Instead, university researchers might have found it more valuable to have contact with different strategically selected people in the institutions. As some of the evaluation conversations also brought up, this situation indicates that university research within topics of museumaudience communication can have different anchorage points - and thus different values - in a museum. Of course, this factor was relevant specifically to those collaborations that involved larger museum institutions (which included the majority of the museums that participated in DREAM).

In this way, the researchers found that becoming broadly acquainted with the museum institutions and museum colleagues, and thus gaining a broad anchorage of personal contacts, was valuable in order for them to bring their insights and contributions to the institutions. Still, several researchers found that whatever personal relations they may have gained at a museum was up to chance. Taking a more strategic approach to establishing multiple contacts at a museum thus might be a worthwhile investment for researchers who wish to investigate and aim to influence museum practices.

\section{Discussion AND CONCLUSION}

This article has presented an analysis and evaluation of university-museum collaborations conducted in the DREAM program. We have focused on mutual contributions and the challenge of generating mutual anchoring between museum professionals and university researchers.
The participants viewed the collaborations as contributing to museum practices by providing concrete knowledge and tools related to developing and evaluating digital learning and communication. In addition, the researchers in several cases challenged the museum professionals' practices and routines and thus helped to spark organizational development and change.

The collaborations contributed to university practices by providing access to an attractive empirical field in which the activities of investigations and design were made possible. The participating researchers emphasized that collaborating closely with museum professionals improved their own calibrations with the realities of museum practices and thus made them into more self-reflective and realistic researchers within this empirical field.

Based on the evaluation conversations and on our own experiences, we conclude that establishing anchorages in form, content, time, and personal relations is pivotal to successful collaboration. As described in our analysis, the different institutional values, priorities, and expectations between universities and museums influenced the collaborations, which led to both compatibilities and incompatibilities when considering all aspects of anchorage. While the four dimensions of anchorage presented in this article might be universally important in all types of collaborations, we have tried to point out the specific circumstances within which these dimensions either thrived or were challenged within the museum-university collaborations in DREAM. In this way, we have specified anchorages within this particular type of collaboration.

While we may conclude that both university and museum partners benefitted from the crossinstitutional collaborations, we also found that 
102 institutional functions and priorities caused the collaborative partners to value different aspects of the collaborations. Specifically, we found that across the projects, a great deal of work still had to be done before genuine integration and anchorage between theoretical and practical approaches to the development of museum-audience communication was achieved. To some extent, this situation may have been because of the specific combination of competencies and expertise found across the collaborations. All the university researchers involved worked with theoretical approaches to communication and learning that stemmed from humanistic or sociological fields, while the museum professionals who were involved either practiced as museum educators or interpreters or worked in a more theoretical and research-based manner across subject areas within cultural, technical, natural, or art history. Between these fields of study and practice, differences existed and were evident in the overall program as well as among the projects. At the same time, the distributions of roles in the projects between curator, museum educator/interpreter and communication researchers were not always easily demarcated and acted out. The fact that someone was a resourceful communication and media researcher or ethnologist, for example, would not always be seen as useful, or necessary, in the encounter with museum educator and museum curator. Instead, some of the collaborations that people often articulated as being the most successful in the DREAM program were those in which the researcher had succeeded in functioning both as a practitioner and as a researcher of museumaudience communication and thus easily demonstrated his or her practical worth to the institution. Oppositely, we did find examples of museum professionals who articulated and reflected on more academic outputs and their ways of gradually changing practices of museum-audience communication within these institutions. On the background of this analysis, we have concluded that finding common research interests and thus genuine anchorages between practical and theoretical expertise related to museum-audience communication - was an overall challenge in the DREAM program that the participants, especially the university researchers, had to continuously reflect and act on.

To reflect further, this challenge of finding genuinely common interests and anchorages at the intersections between the more theoretical and the more practical content of the collaborations might have been caused by at least two aspects of the cross-institutional collaborative form of the DREAM program. First, the program's research objectives were developed by the senior university researchers, and the museum projects were only subsequently selected into that researchbased framework. Even though the museum projects thus had not been initiated, planned for, or sometimes even designed within the research framework of the DREAM program, a large amount of integration between research approaches and the practical projects was still expected. This specific combination of program setup and an aim to closely merge theory and practice could be perceived as very ambitious. The second related point is that the DREAM program was simultaneously viewed as a crossinstitutional program and a research education program. In many ways, training university researchers by letting us conduct research partnerships with external institutions proved very meaningful, but as previously mentioned, the requirements, formalities, and norms related to earning a $\mathrm{PhD}$ degree often forced university research partners to retain specific 
research agendas and approaches that might otherwise have been worth revising or omitting. Thus, a research program that contained both cross-institutional partnerships and research education posed certain challenges when attaining anchorage in terms of form, content, and time.

With this article, we hope to contribute to future museum-university collaborations, by suggesting that anchorage, with its different dimensions of form, content, time and personal relations, should be explicitly and collaboratively reflected on and planned for whenever possible.

\section{Acknowledgements}

The Learning 2.0: Digital Literacies and Innovation DREAM program was supported by the Danish Council for Strategic Research under grant number 09-063275. We would like to thank former DREAM participants Kirsten Drotner, Christina Papsø Weber, Jens Astrup, Anne Rørbæk Olesen for reading earlier drafts of this article.

\section{Notes}

1. https://www.merriam-webster.com/dictionary/ collaborate

2. http://veluxfoundations.dk/da/ museumsprogrammet

3. http://veluxfoundations.dk/da/ museumsprogrammet

4. https://innovationsfonden.dk/da/ investeringstype/grand-solutions

5. https://ec.europa.eu/programmes/horizon2020/ en/h2020-section/science-and-society

6. Masters of Art (MA) in Applied Cultural Analysis, University of Copenhagen.

7. The museums included the ARKEN Museum of Modern Art, the National Gallery of Denmark, the Louisiana Museum of Modern Art, the
Moesgaard Museum, the Roskilde Museum/

Ragnarock, the National Museum of Denmark/

New Trelleborg, the Media Museum, the

Natural History Museum of Denmark, the Blue Planet - Natural Aquarium Denmark, and the Experimentarium.

8. In 200945 million DKK was equivalent to app. 5,3 million GBP.

\section{LITERATURE}

Bruner, Jerome S., Rose R. Olver \& Patricia Marks Greenfield 1966. Studies in Cognitive Growth. New York: Wiley.

Cooper, Catherine L. 2013. "A case study in collaboration. Displaying Greece and Rome at the Fitzwilliam Museum, Cambridge, UK." Museum Management and Curatorship 28:5, 467-490.

Crowley, Kevin \& Karen Knutson 2005. "Museum as learning laboratory. Bringing research and practice together." Hand to Hand 18:5, 3-6.

Danko-McGhee, Katharina 2004. "The museumuniversity connection. Partners in early childhood art experiences." Art Education 57:6, 35-40.

Davis, Pryce, Michael Horn, Florian Block, Brenda Phillips, Margaret E. Evans, Judy Diamond \& Chia Shen 2015. "'Whoa! We're going deep in the trees!' Patterns of collaboration around an interactive information visualization exhibit." International Journal of Computer-Supported Collaborative Learning 10:1, 53-76.

Dodd, Jocelyn, Ceri Jones, Andy Sawyer \& MariaAnna Tseliou 2012. Voices from the Museum. Qualitative Research Conducted in Europe's National Museums. Report from Research Centre for Museums and Galleries, Leicester University.

Drotner, Kirsten 2013. "DREAM og læring 2.0. Brugerorienteret, digital medievidenskab." Nordicom 1-2, 81-85.

Drotner, Kirsten \& Kim C. Schrøder 2013. Museum Communication and Social Media. The Connected Museum. London: Routledge. 


\section{Line VestergaARd Knudsen \& Celia Ekelund Simonsen}

104 Falk, John H. 2009. Identity and the Museum Visitor Experience. London: Routledge.

Gransgaard, Helle, Jens F. Jensen \& Ane Hejlskov Larsen 2014. Dansk Museumsforskning. Status og tendenser. Aalborg: Aalborg Universitetsforlag.

Gronemann, Sigurd T. 2016. Museer, naturvidenskab og sociale medier. Muligheder og udfordringer.

$\mathrm{PhD}$ dissertation. Odense: University of Southern Denmark.

Hooper-Greenhill, Eilean (ed.) 1999. Museum, Media, Message. Abingdon, UK \& New York: Psychology Press.

Knudsen, Line. V. 2015. Rockens Danmarkskort. Deltagelse praktiseret som forskellighed. $\mathrm{PhD}$ dissertation. Roskilde: Roskilde Universitet.

Knutson, Karen \& Kevin Crowley 2005. "Museum as learning laboratory. Developing and using a practical theory of informal learning." Hand to Hand 18:4, 4-5.

Kobbernagel, Christian 2013. Students' learning experiences in digital workshops. A PhD thesis of enquiries into learning and communication and methodological explorations using $Q$ methodology and structural equation modeling in the field of art gallery education. $\mathrm{PhD}$ dissertation. Roskilde: Roskilde University.

Kyed, Steen et al. 2006. Udredning om museernes formidling. København: Kulturministeriet.

Laursen, Ditte 2013. "Co-participation among school children around a computer-based exhibit." Social Studies of Science 43:1, 97-117.

Madsen, Jacob W., Mette T. Mortensen \& Mark Vacher 2014. "Museet som kulturanalytisk case." Danske Museer 1, 13-15.

MacLeod, Suzanne, Richard Sandell, Jocelyn Dodd, Tom Duncan, Ceri Jones \& Alexandra Gaffikin 2014. Prisoners, Punishment and Torture. Developing New Approaches to Interpretation at the Tower of London. Report from the Research Centre for Museums and Galleries, Leicester University.
Olesen, Anne R. 2015. Co-Designing Digital Museum Communication. $\mathrm{PhD}$ dissertation. Roskilde: Roskilde Universitet.

Raith, Sanne 2016. Digital Museum Education. A Comparative Study of Danish Upper-Secondary Students' Interaction and Meaning Making with Digital and Physical Museum Resources in Museums and Schools. PhD dissertation. Roskilde: Roskilde University.

Rudloff, Maja 2013. "Det medialiserede museum. Digitale teknologiers transformation af museernes formidling." MedieKultur. Journal of Media and Communication Research 29:54, 65-86.

Simon, Nina 2010. The Participatory Museum. Santa Cruz, CA: Museum 2.0.

Simonsen, Celia E. 2016. Fra skrappe moster til facilitator. Et studie af skoleelevers kreative loering ved brug af mobile medier på et science center. $\mathrm{PhD}$ dissertation. Odense: University of Southern Denmark.

Vestergaard, Vitus 2012. Det hybride museum. Unge brugeres deltagelse gennem produktion og deling af indhold $i$ et fysisk museumsrum. $\mathrm{PhD}$ dissertation. Odense: University of Southern Denmark.

Line Vestergaard Knudsen, Ph.D., Assistant Professor vestergaard@cgs.aau.dk

Department of Culture and Global Studies Aalborg University PO Box 9220 Aalborg, Denmark

\author{
Celia Ekelund Simonsen, Ph.D., Curator \\ ces@museummidtjylland.dk
}

Museum Midtjylland PO Box 7400 Herning, Denmark 